\title{
Dynamic wage bargaining if benefits are tied to individual wages
}

\author{
By Thomas Beissinger ${ }^{\star}$ and Hartmut Egger $\dagger$ \\ ${ }^{\star}$ Department of Economics, University of Regensburg, \\ D-93040 Regensburg, Germany and IZA, Bonn, Germany; \\ e-mail: thomas.beissinger@wiwi.uni-regensburg.de \\ $\dagger$ Socioeconomic Institute, University of Zurich, Zurich, Switzerland
}

\begin{abstract}
In dynamic wage bargaining models it is usually assumed that individual unemployment benefits are a fraction of the average wage level. In most countries, however, unemployment benefits are instead tied to the previous level of individually earned wages. We show how the analysis has to be modified if this fact is taken into account and compare our findings for the wage-setting curve with outcomes under other unemployment compensation schemes. From this comparison it becomes evident how the shape and position of the wage-setting curve depends on the specification of the unemployment benefit system. We also demonstrate that a reduction of unemployment benefits of those who become unemployed after the bargaining period leads to higher equilibrium unemployment.
\end{abstract}

\section{Introduction}

The literature dealing with dynamic wage bargaining on the firm level in a general equilibrium framework usually makes the following assumptions: ${ }^{1}$ (i) Unemployment benefits are not lump-sum transfers but a function of the wage level. (ii) The functional relationship is such that individual unemployment benefits are a fraction of the average wage level. (iii) Unemployment benefits are the same for persons being already unemployed in the bargaining period and persons becoming unemployed in later time periods.

Due to the presumed large number of firms and labor unions, assumption (ii) implies that the bargaining parties consider unemployment benefits to be exogenous. As a further consequence benefits are identical for all persons becoming unemployed in the same period independent of their previous workplace. Assumption (iii) implies that unemployment benefits do not depend on the time period in which a worker becomes unemployed. This would be the case if unemployment benefits of all unemployed were related to the actual average wage level.

${ }^{1}$ Cf. Layard and Nickell (1990), Manning (1993), and Altenburg and Straub (1998). 
We find assumption (i) to be plausible for most economies, ${ }^{2}$ but argue that assumptions (ii) and (iii) have to be modified. For many real-world economies these assumptions are not a valid description of the institutional setup, since unemployment benefits are usually tied to the previous level of individually earned wages. ${ }^{3}$ In this case one could expect that labor unions will not consider unemployment benefits to be exogenous but will take account of the fact that higher wage claims today imply higher unemployment benefits tomorrow. Moreover, unemployment benefits of those who are unemployed in the bargaining period will differ from benefits of those who become unemployed in later periods.

In this paper we show how the analysis and the results are modified if assumptions (ii) and (iii) are altered. Our theoretical framework encompasses influential models of the literature as special cases. In the comparison of our results with those of the literature, we focus on the case usually considered in the literature, namely the case with risk-neutral workers and Cobb-Douglas technology. From this comparison it becomes evident how the shape and position of the wage-setting curve depends on the specification of the unemployment benefit system.

In addition, the paper contributes to the recent political debate in many European economies stating that unemployment benefits have to be reduced in order to overcome the unemployment problem. In the model of this paper a distinction is made between unemployment benefits of those being unemployed in the bargaining period and those who become unemployed afterwards. It is demonstrated that policies which only reduce benefits of the latter group exhibit adverse effects on wage pressure and lead to higher equilibrium unemployment.

The remainder of the paper is organized as follows. Section 2 presents the theoretical framework and derives the contributions of firms and labor unions to the Nash bargain. Section 3 considers the results of the firm-level wage bargain, which is followed by a discussion of the properties of the aggregate wage-setting curve in Section 4. Section 5 compares our results for the wage-setting curve with those obtained under other unemployment compensation systems. Section 6 describes the general equilibrium and presents comparative-static results for changes in the replacement ratio. Section 7 extends the basic model by allowing for taxes on wage income and unemployment benefits. Section 8 discusses the implications of some of the model's assumptions and Section 9 concludes.

\section{Contributions of firms and labor unions to the Nash bargain}

We consider a closed economy with monopolistic competition in the goods market and wage bargains taking place at the firm level. There are $n$ identical firms and an

\footnotetext{
${ }^{2}$ Exceptions are, for instance, Australia, Great Britain, Iceland, Ireland, Korea, Poland, and New Zealand, where a flat-rate benefit scheme is implemented.

${ }^{3}$ For an international comparison of unemployment compensation systems see, for instance, OECD (1999), Schmid and Reissert (1996), and Schömann et al. (2000).
} 
equal number of identical unions. All firms are unionized and bargain with their own union. Since the number of firms and unions is large, the bargaining parties neglect the consequences of their decisions for the rest of the economy. The values of the objective functions of firms and unions in the case of a successful bargain in period $t$ are denoted as $\Pi_{t}$ and $Z_{t}$, respectively. If an agreement cannot be reached the corresponding values are $\bar{\Pi}_{t}$ and $\bar{Z}_{t}$. The bargaining outcome is obtained by maximizing the asymmetric Nash product $\Omega_{t}=\left(Z_{t}-\bar{Z}_{t}\right)^{\gamma} \times$ $\left(\Pi_{t}-\bar{\Pi}_{t}\right)^{1-\gamma}$, where $\gamma$ describes the bargaining power of labor unions $(0<\gamma<1)$. After the determination of wages employers unilaterally choose the level of employment which guarantees the highest profits. This 'right to manage' of employers is taken into account in the wage bargain. ${ }^{4}$ In order to keep the analysis as simple as possible, the growth process of the economy is not modeled. In other words, technological progress as well as investment and saving decisions are neglected. Instead, it is assumed that the stock of capital is exogenously given and evenly distributed among firms. The main analysis is facilitated by assuming that unemployment benefits are financed by lump-sum taxes on the fixed stock of capital. ${ }^{5}$ In Section 7 it is discussed whether and how the analysis is changed if unemployment benefits are financed by taxes on labor income.

Consider first the employer's side of the wage bargain. If profits are earned at the end of each period, a firm's discounted profits at the beginning of period $t$ are

$$
\Pi_{t}=\frac{1}{1+\rho}\left[R\left(N_{t}\right)-W_{t} N_{t}-F_{t}^{c}+\Pi_{t+1}\right]
$$

where $\rho$ is the discount rate of firms, $N_{t}$ is employment and $W_{t}$ and $F_{t}^{c}$ denote (real) wages and fixed costs, respectively. $\Pi_{t+1}$ denotes discounted profits at the beginning of period $t+1$. For the revenue function $R$ it is assumed that $R_{N}>0$ and $R_{N N}<0$, where $R_{N}$ and $R_{N N}$ are the first and second derivatives of the revenue function with respect to employment. Now assume that in a bargaining period $t$ wages are negotiated for $T$ periods, implying $W_{t}=W_{t+1}=\cdots=W_{t+T-1}$ and $N_{t}=N_{t+1}=\cdots=N_{t+T-1}$. In this case the bargained wage $W_{t}$ will affect $\Pi_{t}, \ldots, \Pi_{t+T-1}$, but not $\Pi_{t+T}$ onwards. If fixed costs are constant for all periods, i.e. $F_{t}^{c}=F^{c}$, the same period profits are obtained in all $T$ periods in which the wage contract is binding. This leads to

$$
\Pi_{t}=\frac{1-v}{\rho}\left[R\left(N_{t}\right)-W_{t} N_{t}-F^{c}\right]+v \Pi_{t+T} \quad \text { with } v \equiv 1 /(1+\rho)^{T}
$$

\footnotetext{
${ }^{4}$ We do not consider the possibility that firms and unions bargain over both wages and employment. The implications of a dynamic efficient bargaining model are discussed in Egger (2002).

${ }^{5}$ The simplifying assumptions with regard to economic growth and taxes are (at least implicitly) also made in other dynamic wage bargaining models. See, for instance, Altenburg and Straub (1998), Layard and Nickell (1990), and Manning (1991).
} 
If no agreement is reached, firms have to incur losses caused by the fixed costs until a new bargaining round takes place. It is assumed that the timing as well as the outcome of the next bargaining round are not affected by the fact that no agreement has been reached in period $t$. Discounted profits of the firm in the no-agreement case are then given by ${ }^{6}$

$$
\bar{\Pi}_{t}=-\frac{1-v}{\rho} F^{c}+v \Pi_{t+T}
$$

With eqs (2) and (3) the firm's contribution to the Nash bargain is

$$
\Pi_{t}-\bar{\Pi}_{t}=\frac{1-v}{\rho}\left[R\left(N_{t}\right)-W_{t} N_{t}\right]
$$

Turning to the union's side of the wage bargain, it is assumed that the contribution of labor unions to the Nash maximand is given by

$$
Z_{t}-\bar{Z}_{t}=N_{t}\left(V_{t}-\tilde{V}_{t}\right)
$$

where $V_{t}$ describes the individual welfare associated with a job within the firm and $\widetilde{V}_{t}$ is the individual welfare associated with being unemployed (both variables referring to period $t$ ). Equation (5) is a standard formulation in the literature, which, for instance, is chosen by Layard and Nickell (1990) and Manning (1991, 1993). ${ }^{7}$ In contrast, Altenburg and Straub (1998) assume that unions do not care about employment. The objective function then reduces to $V-\tilde{V}$, which is formally identical to the one which results in the seniority trade union model discussed by Oswald (1993), if employment in the firm is higher than the minimum employment level at which the worker with median seniority is employed. However, it is conceivable that, along with his own wage, the median member is also interested in employment (cf. Lever and van Veen, 1991). As Pencavel (1985, p.199) puts it: 'Altruism may well not be a relevant factor in a number of cases, but at the same time in parts of North American and West European societies there are deep traditions of working class fellowship and in such instances it would be shortsighted to presume that such sentiments have no behavioral consequences.' Considering the implications of the 'pure' seniority model as too restrictive, we prefer a specification of labor unions' preferences where employment enters the utility function. ${ }^{8}$

\footnotetext{
${ }^{6}$ In Manning (1991) similar expressions for $\Pi_{t}$ and $\bar{\Pi}_{t}$ are derived.

7 The latter author uses a slightly more general specification by allowing for an employment weight which may be different from one.

${ }^{8}$ Alternatively, in Egger (2002) a dynamic bargaining model with Stone-Geary objective function is analysed.
} 
To determine the outcome of the Nash bargain, $V_{t}-\widetilde{V}_{t}$ has to be specified. The model under consideration is deterministic in nature, i.e. stochastic shocks are neglected. Therefore, an exogenous quit rate is introduced into the model to allow for job turnover in the steady state. Let $\delta$ denote the proportion of employees who leave employment and enter unemployment in each period. With the unemployment rate $u$ being constant in the steady state, the probability of an unemployed person for finding a new job, $a$, is endogenously determined by ${ }^{9}$

$$
a=\frac{\delta(1-u)}{u}
$$

An increase in the unemployment rate reduces the probability of getting a new job, i.e. $\partial a / \partial u<0$, whereas a rise in the quit rate enhances the re-employment prospects, i.e. $\partial a / \partial \delta>0$. It is assumed that wages and employment are both determined at the beginning of the period but payments (wages or unemployment benefits) are made at the end of the period. Benefits for an unemployed person depend on the respective wage earned in his last occupation. In the steady state $(u$ constant), at the beginning of any period $t$ the expected lifetime utility $V_{t}$ of an individual who remains employed in period $t$ in the firm under consideration is given by the following present value expression

$$
V_{t}=\frac{1}{1+r}\left[U\left(W_{t}\right)+\delta \bar{V}_{t+1}+(1-\delta) V_{t+1}\right]
$$

where $r$ is the discount rate of workers, which may differ from the discount rate of firms $\rho$, and $U$ denotes the utility function of income. $\bar{V}_{t+1}$ is the expected lifetime utility of a person (at the beginning of period $t+1$ ) who becomes unemployed at the beginning of period $t+1$ and has previously worked in the firm under consideration. It is defined as

$$
\bar{V}_{t+1}=\frac{1}{1+r}\left[U\left(B_{t+1}\right)+a V_{1 t+2}+(1-a) \bar{V}_{t+2}\right]
$$

where $B$ denotes (real) unemployment benefits. A subscript 1 is used to distinguish utility levels and wages (or benefits) of individuals who work in an occupation elsewhere (or have previously worked elsewhere and are now unemployed) from the respective values of individuals who work (or have previously worked) in the firm under consideration. Thus, $V_{1}$ is the expected lifetime utility of a person being

\footnotetext{
${ }^{9}$ It is assumed that each individual has the same re-employment probability. Hence, we do not take into account that individuals may have different unemployment risks due to different qualifications, abilities and so on.
} 
employed elsewhere and is (for period $t$ ) defined by

$$
V_{1 t}=\frac{1}{1+r}\left[U\left(W_{1 t}\right)+\delta \bar{V}_{1 t+1}+(1-\delta) V_{1 t+1}\right]
$$

with

$$
\bar{V}_{1 t+1}=\frac{1}{1+r}\left[U\left(B_{1 t+1}\right)+a V_{1 t+2}+(1-a) \bar{V}_{1 t+2}\right]
$$

$W_{1}$ denotes the wage paid in firms different from the one under consideration. $B_{1}$ are unemployment benefits for persons who previously worked in a firm different from that under consideration. $\bar{V}_{1}$ is the expected lifetime utility of an unemployed person whose last workplace was at a firm elsewhere. In eq. (8) it is implicitly assumed that a person leaving the pool of unemployed will never again get a job in the firm under consideration, since the probability of this event is virtually zero due to the large number of firms. Furthermore, in this model it is assumed that a direct switch from one firm to another is not possible. Workers who want to change their employer first have to enter the pool of the unemployed.

As explained in the introduction we consider an economy where unemployment benefits of individuals are related to their own previous earnings, thereby modifying assumption (ii) which states that benefits are a function of the average wage level. Hence, for those becoming unemployed in period $t+1$ their own wage of period $t$ is relevant for the determination of benefit levels. This has to be taken into account in eqs (8) and (10) implying that $B_{t+1}=b W_{t}$ and $B_{1 t+1}=b W_{1 t}$, where $b$ is the exogenous replacement ratio $(0<b<1)$. Since at the firm level a distinction is made between wages paid by different firms, this modification implies that unemployment benefits may vary between unemployed persons who were previously employed in different firms. Making unemployment benefits dependent on previous individual earnings also implies that assumption (iii) has to be altered. Since wage levels before the bargaining period may differ from wages prevailing afterwards, it follows that also unemployment benefits may be different across time periods.

To show the consequences of a modification of assumptions (ii) and (iii), we focus on the infinite bargain case with $T \rightarrow \infty$ which has been considered by Layard and Nickell (1990) and Hoel (1991). ${ }^{10}$ It is assumed that a symmetric equilibrium prevailed before the bargaining period $t=t_{0}$ implying that wages and unemployment benefits were the same for all individuals. At the beginning of period $t_{0}$ in each firm unique wage and employment levels are chosen for this and all future periods. As a result the (new) steady state will already be reached

\footnotetext{
${ }^{10}$ In the finite bargain case additional problems arise since the steady state concept applied by Layard and Nickell (1990) and Manning (1991) cannot be used if future wage levels are influenced by today's bargain.
} 
in period $t_{0}$. Omitting time indices for steady state values, eqs (7) to (10) become

$$
\begin{gathered}
V=\frac{1}{1+r}[U(W)+\delta \bar{V}+(1-\delta) V] \\
\bar{V}=\frac{1}{1+r}\left[U(b W)+a V_{1}+(1-a) \bar{V}\right] \\
V_{1}=\frac{1}{1+r}\left[U\left(W_{1}\right)+\delta \bar{V}_{1}+(1-\delta) V_{1}\right] \\
\bar{V}_{1}=\frac{1}{1+r}\left[U\left(b W_{1}\right)+a V_{1}+(1-a) \bar{V}_{1}\right]
\end{gathered}
$$

Additionally one obtains

$$
\tilde{V}=\frac{1}{1+r}\left[U\left(B_{t_{0}}\right)+a V_{1}+(1-a) \tilde{V}\right]
$$

where $B_{t_{0}}$ denotes the level of unemployment benefits for those persons who entered unemployment before or in the bargaining period. Since benefits depend on wages paid by the previous employer, one must distinguish the expected lifetime utility of a person who gets unemployed after the bargaining period and has previously worked in the firm under consideration, $\bar{V}$, from the expected lifetime utility of a person who gets unemployed before or in the bargaining period, $\widetilde{V}$. The reason is that wage levels and hence unemployment benefits before and after the wage bargain may differ.

Figure 1 gives an idea of how the intertemporal structure of the model is simplified by the assumption of an infinite wage bargain. An important aspect is that from period $t=t_{0}$ onwards it does not matter in which period a person gets unemployed. It is only relevant whether the last workplace was at the firm under consideration or at a firm elsewhere in the economy. In other words: a person who becomes unemployed after the bargaining period always gets unemployment benefits $b W$ if the last workplace was at the firm under consideration, and unemployment benefits $b W_{1}$ otherwise.

Our framework is more complex then the infinite bargaining framework usually considered in the literature. The reason is that in the literature it is assumed that unemployment benefits of all unemployed are always related to the actual average wage level. For the latter case, the lifetime utility $V$ is depicted in Fig. 2. Since unemployment benefits of all unemployed are equal to $b W_{1}$, the present discounted value of the utility stream of an unemployed person is always equal to $\bar{V}_{1}$. Moreover, since unemployment benefits are always related to the actual wage level, the expression for $\widetilde{V}$ of eq. (15) equals the expression for $\bar{V}_{1}$. 
$\begin{array}{lll}t+1 & t+2 & t+3\end{array}$

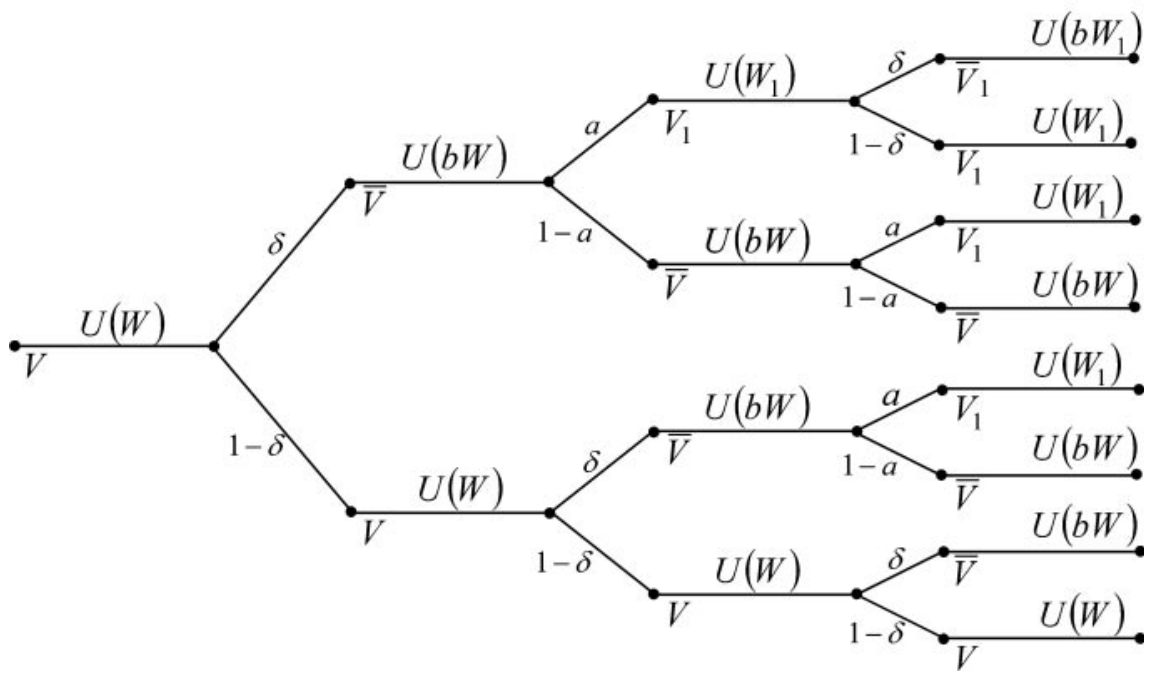

Fig. 1. Lifetime utility $V$ in the case of an infinite wage bargain and unemployment benefits being tied to the previous level of individually earned wages.

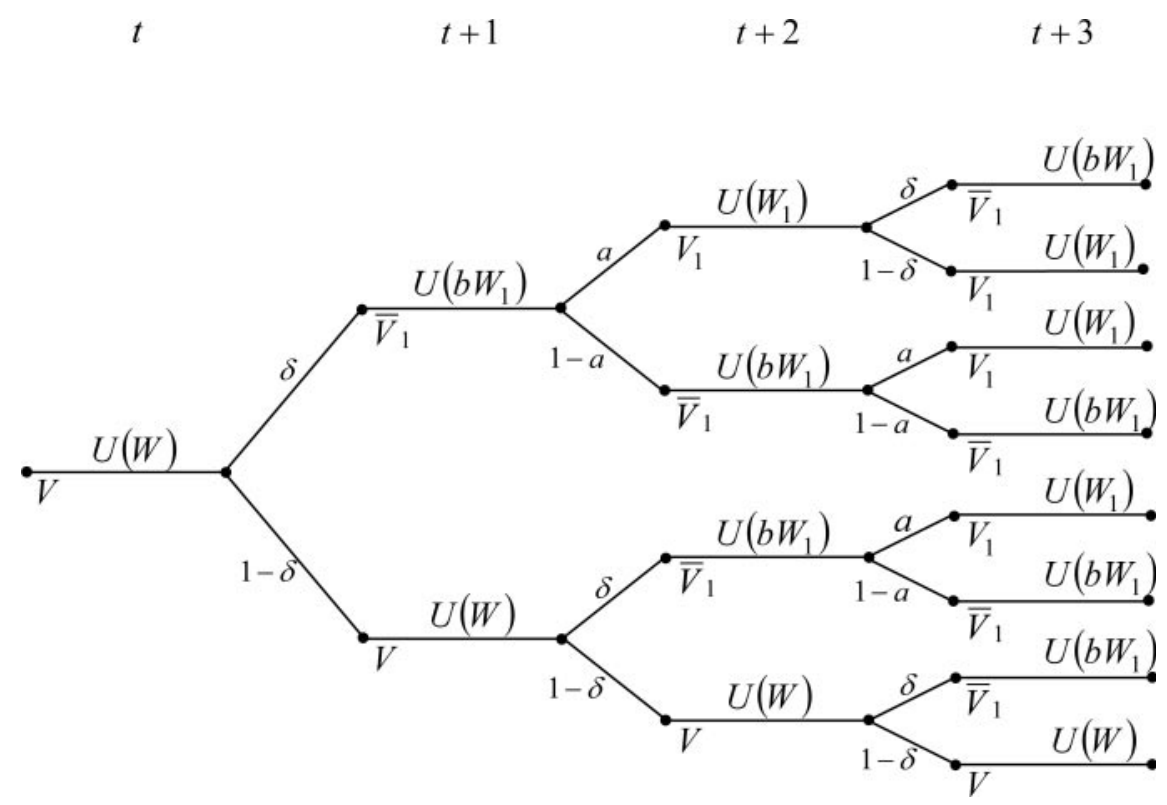

Fig. 2. Lifetime utility $V$ in the case of an infinite wage bargain and unemployment benefits being tied to the actual average wage level. 
Turning back to our framework, from eqs (11) to (15) and eq. (6) it can be deduced that

$$
V-\widetilde{V}=\frac{1}{r+\delta}[U(W)-\bar{U}(W)]
$$

where

$$
\bar{U}(W) \equiv[1-\omega(u)] U\left(W_{1}\right)+\tau(u) U\left(B_{t_{0}}\right)+\psi(u) U\left(b W_{1}\right)-\lambda(u) U(b W)
$$

The functions containing the unemployment rate as argument are defined as

$$
\begin{gathered}
\tau(u) \equiv \frac{(r+\delta) u}{(1-u) \delta+r u} \geq 0, \psi(u) \equiv \frac{(1-u) u \delta^{2}}{(r u+\delta)((1-u) \delta+r u)} \geq 0 \\
\lambda(u) \equiv \frac{\delta u}{(1-u) \delta+r u} \geq 0 \\
\omega(u) \equiv \tau(u)+\psi(u)-\lambda(u)=\frac{(r+\delta) u}{r u+\delta} \geq 0
\end{gathered}
$$

where the equality sign in all expressions holds for $u=0$ (and in the case of $\psi(u)$ also for $u=1)$. It can also be seen that $\lambda(u)<\tau(u)$ for all unemployment rates $u>0$. Furthermore, $\omega(u) \leq 1$, where the equality sign holds for $u=1$.

\section{Firm-level wage bargain}

With the theoretical framework in place, the result of the wage bargain can be derived. Taking account of eqs (4), (5), and (16), the right-to-manage bargaining result is obtained by maximizing the Nash product

$$
\Omega_{t_{0}}=\{N[U(W)-\bar{U}(W)]\}^{\gamma}\{R(N)-W N\}^{1-\gamma}, \quad \text { s.t. } R_{N}-W=0
$$

with respect to $W$ and $N$. The constraint in eq. (19) reflects the fact that firms choose a point on the labor demand curve. ${ }^{11}$ After some transformations the following first order condition is obtained

$$
\frac{\left[U_{W}-\bar{U}_{W}\right] W}{U(W)-\bar{U}(W)}=\mu \quad \text { where } \mu \equiv \varepsilon_{N, W}+\frac{1-\gamma}{\gamma} \frac{\varepsilon_{R, N}}{1-\varepsilon_{R, N}}
$$

\footnotetext{
${ }^{11}$ The constant factors $1 / \rho$ and $1 /(r+\delta)$ are omitted, since they have no influence on the Nash solution (note that in the infinite bargain case $\lim _{T \rightarrow \infty} v=0$ ).
} 
$U_{W}$ and $\bar{U}_{W}$ denote the derivatives of $U$ and $\bar{U}$ with respect to $W . \varepsilon_{N, W} \equiv$ $-R_{N} /\left(N R_{N N}\right)$ is the elasticity of labor demand with respect to wages (in absolute values), and $\varepsilon_{R, N} \equiv\left(N R_{N}\right) / R$ denotes the elasticity of revenues with respect to employment.

In the literature the analysis is usually restricted to the case with an isoelastic goods demand function of the Blanchard and Kiyotaki (1987) type. Defining $\kappa$ as $\kappa \equiv(\eta-1) / \eta$, where $\eta$ is the constant elasticity of demand $(\eta>1)$, and describing technology by means of the production function $F(N, K)$, where $K$ is the fixed stock of capital, one obtains

$$
R_{N}=\frac{\kappa R F_{N}}{F} \quad \text { and } \quad R_{N N}=R_{N} \frac{F_{N N}}{F_{N}}-(1-\kappa) R_{N} \frac{F_{N}}{F}, \quad \text { with } 0<\kappa<1
$$

$F_{N}>0$ and $F_{N N}<0$ denote the first and second partial derivative of $F$ with respect to $N$. The higher the degree of competition on the goods market (described by a higher elasticity of the demand for goods) the higher is the parameter $\kappa$. If it is assumed that the production function is linear-homogenous the expression $\mu$ defined in eq. (20) can be written as

$$
\mu=\frac{1}{(1-\kappa) \varepsilon_{Y, N}+\frac{1}{\sigma}\left(1-\varepsilon_{Y, N}\right)}+\frac{1-\gamma}{\gamma} \frac{\kappa \varepsilon_{Y, N}}{1-\kappa \varepsilon_{Y, N}}
$$

In this equation $\varepsilon_{Y, N}$ denotes the elasticity of output with respect to employment and $\sigma$ the elasticity of substitution between employment and capital. In the CobbDouglas case with $F(N, K)=N^{\alpha} K^{1-\alpha}$, it follows that $\varepsilon_{Y, N}=\alpha$ and $\sigma=1$. Hence, the expression $\mu$, which in general depends on $W$ and $N$, becomes constant if the production function is of the Cobb-Douglas type. In order to derive a solution which is directly comparable with the respective results in the literature, we restrict our analysis to the case with isoelastic goods demand and CobbDouglas technology. Furthermore, we assume that workers are risk-neutral, which implies that $U(W)=W$ and $U(b W)=b W \cdot{ }^{12}$ In this case $\bar{U}(W)$, which is defined in eq. (17), can be written as ${ }^{13}$

$$
\bar{U}(W) \equiv[1-\omega(u)] W_{1}+\tau(u) B_{t_{0}}+\psi(u) b W_{1}-\lambda(u) b W
$$

\footnotetext{
12 The following analysis would also be valid in a somewhat more general model variant with isoelastic utility functions of workers $U(W)=W^{\beta} / \beta$, which has also been considered in the literature. To simplify the exposition we restrict the analysis to the case with $\beta=1$.

${ }^{13}$ The imposed restrictions also are sufficient conditions to guarantee a unique bargaining solution in the right-to-manage model. For a detailed discussion see Alexander and Ledermann (1996).
} 
Due to eq. (20) the following wage is chosen on the firm level

$$
W=\frac{\mu}{\mu-1} \frac{1}{1+\lambda(u) b}\left\{[1-\omega(u)] W_{1}+\tau(u) B_{t_{0}}+\psi(u) b W_{1}\right\}
$$

where $\mu$ is constant in the Cobb-Douglas case. For $W>0$ the condition $\mu>1$ must hold.

\section{The aggregate wage-setting curve}

As a next step the aggregate wage-setting curve will be derived. Since all bargaining units are identical, in the general equilibrium $W_{1}=W$ must hold. In Appendix 1 it is shown that the following aggregate wage-setting equation results

$$
W=W(u)=\frac{\mu \tau(u)}{[1+\lambda(u) b][\mu \omega(u)-1]} B_{t_{0}}
$$

For $W>0$ it must hold that $\mu \omega(u)-1>0$. Hence, the wage-setting curve is only defined for $u \in(\underline{u}, 1]$, where $\underline{u}=\delta /[\mu \delta+(\mu-1) r]$ determines the lower bound for the unemployment rate. It can be shown that $W>B_{t_{0}}$ for all permissible values of $u$. A lower $\mu$ implies that on the firm level the wage mark-up on the outside alternative income rises. For this reason a lower $\mu$ ceteris paribus leads to a higher wage-setting curve in real wage-unemployment space. ${ }^{14}$

In the current debate about remedies for the unemployment problem it is often claimed that unemployment benefits must be reduced to lower wage pressure and hence unemployment. ${ }^{15}$ With respect to $B_{t_{0}}$, which are unemployment benefits of those who are unemployed in the bargaining period, such claims seem to be confirmed by eq. (24), since a reduction of $B_{t_{0}}$ leads to a lower wage-setting curve. Interestingly, the opposite result is obtained if the replacement ratio $b$ is changed and unemployment benefits $B_{t_{0}}$ are held constant. Such a situation may arise if in the bargaining period the government announces that unemployment benefits of those who become unemployed after the bargaining period will be reduced, whereas the payments to the currently unemployed remain unchanged. As can be seen from eq. (24), a reduction in the replacement ratio $b$ with given $B_{t_{0}}$ leads to higher wage pressure. The reason for this surprising result is that a reduction of $b$ lowers the costs of a wage increase more than the corresponding gains, thus provoking higher wage claims at a given unemployment rate. ${ }^{16}$

\footnotetext{
${ }^{14}$ We also scrutinized the implications of a changing $\delta$ or $r$ for the location and shape of the wage-setting curve. However, the resulting expressions turned out to be rather complicated and difficult to interpret. Due to a different focus of this paper we omit a discussion of the impact of these parameters on the wage-setting curve.

${ }^{15}$ In recent years unemployment benefits have already been reduced in several countries, as, for example, Austria, Canada, Germany, and Sweden. See Schömann et al. (2000) for an overview.
} 
Next we compute the slope of the wage-setting curve, which due to eq. (24) leads to

$$
\frac{d W(u)}{d u}=\frac{\mu \tau^{\prime}(u) q(u)-\mu \tau(u) q^{\prime}(u)}{[q(u)]^{2}} B_{t_{0}}
$$

where $q(u) \equiv[1+\lambda(u) b][\mu \omega(u)-1]>0$. In Appendix 2 it is demonstrated that

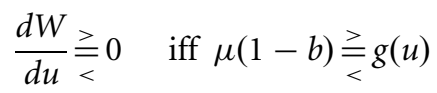

where $g(u) \equiv(\delta+r u)^{2} /\left[\delta u^{2}(\delta+r)\right]$. Since $g^{\prime}(u)<0$ it follows that the right-hand side of eq. (26) declines with increases in $u$. Due to the assumption that $\mu>1$ it is easy to show that $\mu(1-b)<\left.g(u)\right|_{u=u}$. Hence, for $u \rightarrow \underline{u}$ the wage-setting curve has a negative slope, i.e. $d W(u) / \bar{d} u<0$. Since for $u \rightarrow \underline{u}$ the expression $[\mu \omega(u)-1]$ approaches zero, it follows from eq. (25) that for $u \rightarrow \underline{u}$ the slope of the wage-setting curve approaches $-\infty$.

For $u=1$ one obtains $g(1)=(\delta+r) / \delta$. Thus, two cases must be distinguished. If $\mu(1-b) \leq(\delta+r) / \delta$ the wage-setting curve does not have a positive slope at $u=1$. Together with $g^{\prime}(u)<0$ it can be concluded that the wage-setting curve falls over the whole range $(\underline{u}, 1]$. However, if $\mu(1-b)>(\delta+r) / \delta$ the wage-setting curve has a positive slope at $u=1$. In this case there exists a negatively and positively sloped bough of the wage-setting curve.

To obtain some intuition for the slope of the wage-setting curve consider first a situation with low unemployment. An increase in the unemployment rate then implies worse outside opportunities at the firm level (at given wages $W_{1}$ ), thereby reducing wage pressure. In the general equilibrium this effect is reinforced by the fact that wages $W_{1}$ in all firms decline and that future unemployment benefits, which are linked to wages, will be lower. However, the unemployment rate may eventually reach a critical level at which unions drive up their wage demands again if the unemployment rate increases. Intuitively this can be explained in the following way: on the one hand, a higher unemployment rate increases the weight of current unemployment benefits $B_{t_{0}}$ (in the consideration of unions), and also increases the weight of future benefits $b W$ of those who remain at work in the

\footnotetext{
${ }^{16}$ The costs and gains of a wage increase are given by $[V(W)-\tilde{V}] N^{\prime}(W)$ and $V^{\prime}(W) N$, respectively, both expressions depending on $b$. The decline in costs is due to the fact that $V$ declines by more than $\widetilde{V}$ which is due to different discount factors (the probability for getting unemployment benefits $b W$ is higher for an employed person than for a person who is unemployed in the bargaining period and must be reemployed before benefits $b W$ are obtained in the following unemployment spells). The decline in the gains of a wage increase is due to the fact that future benefits, which depend on current wages, are rising less if $b$ is lower.
} 
bargaining period. On the other hand, future unemployment benefits decline if real wages determined by the bargaining parties go down. If real wages are low and the unemployment rate is high enough, the welfare loss of an additional unemployed member may become lower than the welfare gain of higher wages for those who remain at work (remember that $B_{t_{0}}$ is exogenously given). In this case wage demands of unions increase. Since all unions behave identical, average wages go up improving the outside opportunities of workers. This gives rise to higher wage demands again. As a result, the aggregate wage-setting curve may have a positively sloped bough.

\section{Comparison with other unemployment compensation schemes}

5.1 Earnings-related benefits as a function of the actual average wage level It is useful to contrast the wage-setting curve implied by eq. (24) with the wage-setting curve which results under the usual assumptions (ii) and (iii) of the literature. These assumptions correspond to an unemployment compensation scheme in which benefits of all unemployed are always related to the actual average wage level. In this case unemployment benefits are the same across individuals and time periods, i.e. $B_{t_{0}}=b W=b W_{1}$ in the above equations. Equation (22) can then be simplified to

$$
\bar{U} \equiv[1-\omega(u)] W_{1}+\omega(u) b W_{1}
$$

with $\omega(u)$ being defined in eq. (18). ${ }^{17}$ Hence, $\bar{U}$ does not depend on individual wages and does not include an exogenous benefit component $B_{t_{0}}$. Using eq. (22a) instead of eq. (22) in the above analysis would lead to the following aggregate wagesetting equation

$$
1=\mu(1-b) \omega(u)
$$

This equation has completely different implications compared to the one derived in eq. (24). Since in eq. (24a) only the unemployment rate shows up as endogenous variable, the wage-setting curve is vertical. This implies that the wage-setting equation alone already determines the equilibrium rate of unemployment $u^{*}$, with

$$
u^{*}=\frac{\delta}{(r+\delta)(1-b) \mu-r}
$$

${ }^{17}$ Equation (22a) results, for instance, in the model of Layard and Nickell (1990, p.781). 
A permissible solution requires that $u^{*} \in[0,1]$ and therefore $(1-b) \mu \geq 1{ }^{18}$ Due to eq. (27) a reduction in $b$ leads to lower equilibrium unemployment. The reason is that in this model variant a lower $b$ not only reduces future unemployment benefits but also benefits of the currently unemployed.

A vertical wage-setting curve has often been used in the literature since it is in line with the stylized fact that labor demand shifts caused by technological change have no (long-run) impact on the level of unemployment, see Layard et al. (1991). To obtain a vertical curve not only must be assumed that workers have isoelastic utility functions and that production is of the Cobb-Douglas type, but, in addition, it is also necessary to restrict the analysis to a model variant with a special institutional setup of the unemployment compensation system.

\subsection{Earnings-related benefits as a function of the average wage level which prevailed when becoming unemployed}

The crucial assumption for a vertical wage-setting curve is assumption (iii) which requires that unemployment benefits are the same for persons being already unemployed in the bargaining period and persons becoming unemployed in later time periods. The importance of this assumption can be seen by analyzing a model variant where this assumption is not made, but assumption (ii) is maintained. This amounts to an unemployment compensation scheme in which unemployment benefits are related to the average wage level which prevailed during the last employment spell of the respective person. In this case in eq. (22) the term $(b W)$ must be replaced by $\left(b W_{1}\right)$, whereas $B_{t_{0}}$ denotes benefits which are related to the previous average wage level (prevalent before the wage bargain took place), i.e.

$$
\bar{U} \equiv[1-\omega(u)] W_{1}+\tau(u) B_{t_{0}}+[\psi(u)-\lambda(u)] b W_{1}
$$

In this case the aggregate wage-setting equation can be written as

$$
W=\widetilde{W}(u)=\frac{\mu \tau(u)}{\mu[\tau(u)+(\psi(u)-\lambda(u))(1-b)]-[1+\lambda(u) b]+\lambda(u) b} B_{t_{0}}
$$

Taking account of the explanations in Appendix 1, the wage-setting equation can be transformed to

$$
W=\tilde{W}(u)=\frac{\mu \tau(u)}{[1+\lambda(u) b][\mu \omega(u)-1]+\lambda(u) b} B_{t_{0}}
$$

\footnotetext{
${ }^{18}$ With $\delta>0$ the result $u^{*}=0$ is not possible. It will be later shown that at $u^{*}=1$ no equilibrium exists since for $u \rightarrow 1$ the slope of the aggregate labor demand curve approaches infinity. The condition $(1-b) \mu>1$ guarantees that $0<u^{*}<1\left(u^{*}>0\right.$ is satisfied if $\left.(1-b) \mu>r /(r+\delta)\right)$.
} 
For $\tilde{W}(u)>0$ the denominator of eq. (24b) must be positive. For this to hold it is sufficient that $u>\underline{u}$, since in this case $\mu \omega(u)-1>0 .{ }^{19}$ From a comparison of eqs $(24)$ and $(24 \mathrm{~b})$ in the interval $(\underline{u}, 1]$ it follows that wage pressure is ceteris paribus higher if unemployment benefits are a function of individual wages instead of the average wage level. Since the denominator in eq. (24) is smaller, for all permissible values of $u$ the respective wage-setting curve lies strictly above the wage-setting curve implied by eq. (24b). The intuition for this result is that unions take into account that higher wages today mean higher benefits for its members tomorrow if unemployment benefits depend on individual wages. This leads to higher wage pressure. Similar to eq. (24) it also follows from eq. (24b) that a reduction in the future replacement ratio $b$ at current benefit levels $B_{t_{0}}$ increases wage pressure. It can therefore be concluded that for this surprising result to hold it is not necessary that unemployment benefits depend on individual wage levels.

Differentiating $\widetilde{W}(u)$ with respect to $u$ leads to

$$
\frac{d \widetilde{W}(u)}{d u}=\frac{\mu \tau^{\prime}(u) \widetilde{q}(u)-\mu \tau(u) \widetilde{q}^{\prime}(u)}{[\widetilde{q}(u)]^{2}} B_{t_{0}}
$$

where $\widetilde{q}(u) \equiv[1+\lambda(u) b][\mu \omega(u)-1]+\lambda(u) b$. Performing the same analysis as described in Appendix 2 and using $\lambda^{\prime}(u) \tau(u)=\lambda(u) \tau^{\prime}(u)$, it can be seen that the same condition for the slope of the wage-setting curve as in eq. (26) is obtained, i.e.

$$
\frac{d \widetilde{W}}{d u} \underset{<}{\gtrless} \quad \text { iff } \mu(1-b) \underset{<}{\gtrless} g(u)
$$

where the function $g(u)$ is defined after eq. (26). As a result, in the interval $(\underline{u}, 1]$ the slope of the wage-setting curve $\widetilde{W}(u)$ has the same sign as the slope of the wagesetting curve $W(u)$ determined by eq. (24).

\subsection{Intertemporally constant flat-rate unemployment benefits}

For some countries a flat-rate unemployment compensation scheme, where all unemployed earn a constant payment $B$, is typical. Substituting $B$ for $b W, b W_{1}$ and $B_{t_{0}}$ in eq. (22) leads to

$$
\bar{U} \equiv[1-\omega(u)] W_{1}+\omega(u) B
$$

In this case the following aggregate wage-setting equation is obtained

$$
W=\bar{W}(u)=\frac{\mu \omega(u)}{\mu \omega(u)-1} B
$$

\footnotetext{
${ }^{19}$ Although the wage-setting equation in eq. (24b) is also valid for unemployment rates lower than $\underline{u}$ we only consider the interval $(\underline{u}, 1]$, in which a comparison with the other wage-setting curves is possible.
} 
For $\bar{W}(u)>0$ it is required that $\mu \omega(u)-1>0$. Hence, the corresponding wagesetting curve is defined for the same interval $(\underline{u}, 1]$ as the wage-setting curve in eq. (24). The wage-setting curve implied by eq. (24c) falls over the whole range $u \in(\underline{u}, 1]$ since unemployment benefits do not depend on real wages determined in the bargaining process. If it is assumed that $B=B_{t_{0}}$, it can be derived that the wage-setting curve defined by eq. (24c) lies strictly below $W(u)$ defined by eq. (24). ${ }^{20}$ The reason is that rising wages do not lead to higher unemployment benefits, which ceteris paribus leads to lower wage pressure.

\subsection{Intertemporally varying flat-rate unemployment benefits}

As a final step, we consider the implications of a flat-rate unemployment compensation scheme with different benefit levels for those persons who entered unemployment before or in the bargaining period $(\widetilde{B})$ and persons becoming unemployed in later periods $(B)$. Substituting $\widetilde{B}$ for $B_{t_{0}}$ and $B$ for $b W_{1}$ and $b W$ in eq. (22) leads to

$$
\bar{U}=[1-\omega(u)] W_{1}+\omega(u) B-\tau(u)(B-\widetilde{B})
$$

where it has been taken into account that $\psi(u)-\lambda(u)=\omega(u)-\tau(u)$. The aggregate wage-setting curve is then given by

$$
W=\hat{W}(u)=\frac{\mu \omega(u)}{\mu \omega(u)-1}\left\{B-\frac{\tau(u)}{\omega(u)}(B-\widetilde{B})\right\}
$$

Note that for $\widetilde{B}=B$ eq. (24c) is obtained. It can be shown that $B \geq \widetilde{B}$ is sufficient for a negatively sloped wage-setting curve in the interval $(\underline{u}, 1]$, while $\hat{W}(u)$ may exhibit a positively sloped bough if $B<\widetilde{B} .^{21}$ With respect to the impact of unemployment benefits $B$ and $\widetilde{B}$ the following results are obtained: A reduction of flatrate benefits $\widetilde{B}$ for those persons who are unemployed in the bargaining period reduces wage pressure and therefore unemployment. However, a reduction of flatrate benefits $B$ for those persons who become unemployed after the bargaining period has the opposite effects. This result can be derived from eq. (24d) by noting that $\tau(u) / \omega(u)>1$ for $u>0$ (and hence for $u>\underline{u}$ ). Together with the results in Section 4 and Subsection 5.2 it can be concluded that the 'perverse' impact on wage pressure caused by a change in unemployment benefit levels for the future unemployed does not depend on whether benefits are earnings-related or paid as flat-rate transfers.

\footnotetext{
${ }^{20}$ This can be seen by taking into account that $\tau(u)-\omega(u)=\omega(u) \lambda(u)$.

${ }^{21}$ The derivation of these results is available from the authors upon request.
} 


\section{The general equilibrium}

In this section we consider the general equilibrium which results with the wagesetting curve derived in eq. (24). For the general equilibrium also the aggregate labor demand curve must be taken into account. With isoelastic goods demand, Cobb-Douglas technology and the assumption of a symmetric equilibrium the equation for aggregate labor demand is

$$
W=H(u)=\alpha \kappa\left(\frac{\bar{K} / L}{(1-u)}\right)^{1-\alpha}
$$

where $\bar{K}$ and $L$ denote the total stock of capital and the labor supply. It is evident that the aggregate labor demand curve has a positive slope in real wage-unemployment space, with $\lim _{u \rightarrow 1} H^{\prime}(u)=\infty$. Since the wage-setting curve of eq. (24) has a finite value at $\left.W(u)\right|_{u=1}$ and since $\lim _{u \rightarrow \underline{u}} W^{\prime}(u)=-\infty$ it follows that an equilibrium exists. If $W(u)$ is falling over the whole range $(\underline{u}, 1]$, the uniqueness of equilibrium is guaranteed. If the wage-setting curve has a positive bough over some part of the interval, multiple equilibria may exist from a theoretical point of view (depending on the parameter constellation). However, if in simulation experiments plausible ranges for the various parameters are chosen, it turns out that a unique equilibrium is obtained.

Consider as an example Fig. 3a where two wage-setting curves with different replacement ratios $b$ are plotted. ${ }^{22}$ As can be seen from Fig. 3a both wage-setting curves have a positive bough. The positively sloped parts of the two wage-setting curves seem to be relevant only for (unrealistically) high levels of the unemployment rate. However, it can be shown that for a sufficiently low level of the bargaining power of labor unions, $\gamma$, both wage-setting curves have a minimum at an unemployment rate lower than $u=0.1$. This implies that the positively sloped bough of $W(u)$ becomes relevant if union power declines, a trend that has often been emphasized in the empirical literature on trade union membership, see Calmfors et al. (2001).

In Fig. 3a the wage-setting curve with the replacement ratio $b=0.3$ lies above the wage-setting curve with the higher replacement ratio $b=0.6$. In Fig. $3 \mathrm{~b}$ the aggregate labor demand curve is depicted. It can be seen that the slope of this curve is getting very steep with high unemployment rates and for $u \rightarrow 1$ approaches infinity. Figure $3 \mathrm{c}$ shows only a small range for the unemployment rate where wage-setting curve and aggregate labor demand curve intersect in the general equilibrium. Since to the right of the intersection point the aggregate labor demand curve lies above the wage-setting curve and since with higher unemployment rates the slope of the labor demand curve increases more than the slope of the

\footnotetext{
${ }^{22}$ For this figure we chose $\kappa=0.9$, a labor income share $\alpha \kappa=0.7, r=0.06, \gamma=0.25, B_{t_{0}}=0.4$ and $\delta=0.07$. To obtain consistent values for $\bar{K} / L$ in the aggregate labor demand equation we used the relationship $r=(1-\alpha) \kappa((\bar{K} / L) /(1-\widetilde{u}))^{-\alpha}$, and set $\widetilde{u}=0.06$.
} 


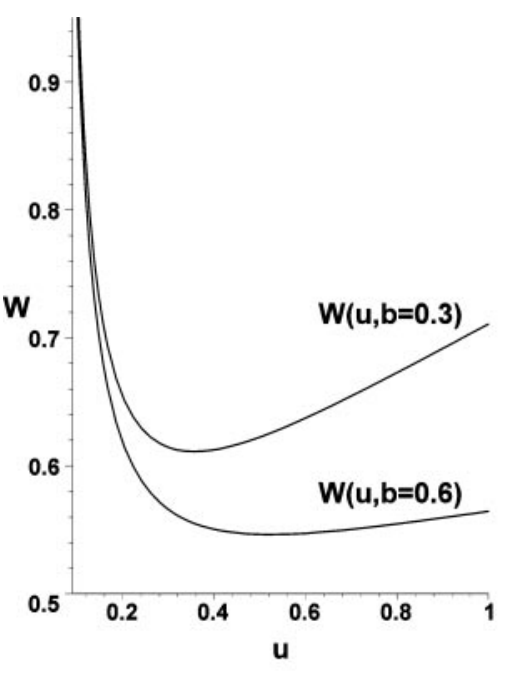

(a) Wage setting curves with diffrent replacement values

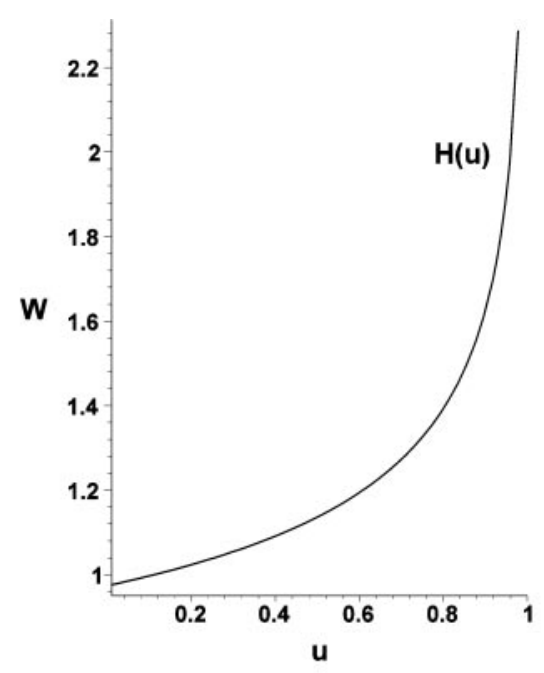

(b) Aggregate labor demand curve

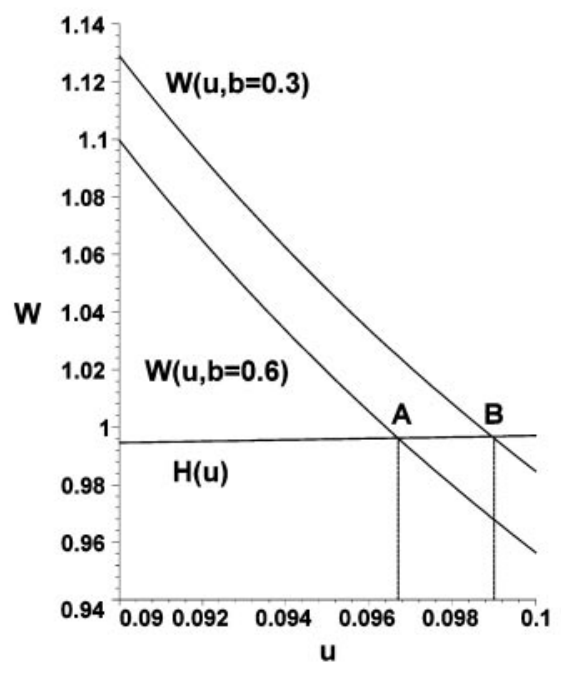

(c) General equilibrium

Fig. 3. The consequences of a decrease in the replacement ratio.

wage-setting curve (along the positive bough), a unique equilibrium is obtained. Figure $3 \mathrm{c}$ confirms the analytical result that a lower replacement ratio for future unemployment benefits leads to higher wage pressure and hence higher unemployment. However, a significant reduction in $b$ from 0.6 to 0.3 has a rather small effect on the unemployment rate which increases from 9.67 to $9.9 \%$. 


\section{Taxes on wage income and unemployment benefits}

So far we have assumed that unemployment benefits are financed by lump-sum taxes on the fixed stock of capital. This assumption seems to be at odds with the large tax burden on labor income in real-world tax systems. In many countries unemployment benefits also are subject to income taxation. Moreover, in most countries with earnings-related benefits, unemployment compensation is related to gross income, see OECD (1999). To account for the role of labor income taxation, we define $W^{n} \equiv\left(1-s_{W}\right) W$ and $W_{1}^{n} \equiv\left(1-s_{W}\right) W_{1}$ as net wages and $b^{n} \equiv\left(1-s_{b}\right) b$ as the replacement ratio relevant for those who entered unemployment after the bargaining period $t_{0}$. The parameter $s_{W}$ and $s_{b}$ denote the tax rates on wage income and unemployment benefits, respectively. Moreover, $B_{t_{0}}^{n} \equiv\left(1-s_{b}\right) B_{t_{0}}$ denotes the level of unemployment benefits for those persons who entered unemployment before or in the bargaining period. By replacing $W, W_{1}, b$, and $B_{t_{0}}$ by their respective net values in eqs (11)-(15) and again assuming risk-neutral workers, the following Nash product is maximized

$$
\Omega_{t_{0}}=\{N[U(\cdot)-\bar{U}(\cdot)]\}^{\gamma}\{R(N)-W N\}^{1-\gamma}, \quad \text { s.t. } R_{N}-W=0
$$

where

$$
U(\cdot)-\bar{U}(\cdot) \equiv W^{n}-[1-\omega(u)] W_{1}^{n}-\tau(u) B_{t_{0}}^{n}-\psi(u) b^{n} W_{1}+\lambda(u) b^{n} W
$$

Following the steps of the analysis in Section 3, instead of eq. (24) the following equation is obtained

$$
W=W^{s}(u)=\frac{\mu \tau(u)}{\left[1+\lambda(u) b^{s}\right][\mu \omega(u)-1]} B_{t_{0}}^{s}
$$

where $b^{s} \equiv b\left(1-s_{b}\right) /\left(1-s_{w}\right)$ and $B_{t_{0}}^{s} \equiv B_{t_{0}}\left(1-s_{b}\right) /\left(1-s_{w}\right)$. Two cases can be distinguished: First, if tax rates on wages and unemployment benefits are equal, i.e. if $s_{W}=s_{b}$, eqs. (24) and (31) coincide, implying that taxes have no impact on gross wages. In this case the analysis of Sections 4-6, which then determines gross wages, remains unchanged. Net wages can be computed by $W^{n} \equiv\left(1-s_{W}\right) W$, where $s_{w}$ is determined by the government budget constraint.

Second, it is often the case that the government imposes a lower tax burden on unemployment benefits. Consider as an example a situation where $\left(1-s_{b}\right)=$ $\left(1-s_{W}\right) \phi$, with $\phi>1$. This implies that the net income share of unemployed workers is higher than the net income share of employees, i.e. $\left(b^{n} W\right) /(b W)=$ $B_{t_{0}}^{n} / B_{t_{0}}>W^{n} / W$. In this case, $b^{s}=b \phi$ and $B_{t_{0}}^{s}=B_{t_{0}} \phi$ in eq. (31). This leads to

$$
W=W^{\phi}(u)=\frac{\mu \tau(u)}{[1+\lambda(u) b \phi][\mu \omega(u)-1]} B_{t_{0}} \phi
$$

Thus, our results of Sections 4-6 remain valid with the only difference that $b$ and $B_{t_{0}}$ have to be substituted by $b \phi$ and $B_{t_{0}} \phi$, respectively. 


\section{Further discussion}

In line with the literature on dynamic wage bargaining it has been assumed that wage bargains take place at the firm level. There is a large number of small bargaining units which implies that (1) they neglect the impact of their decisions on the aggregate economy and (2) they do not behave strategically. However, in many economies wage bargains take place at the industry or national level. From the work of Calmfors and Driffill (1988) and others it is well-known that this may affect the position and perhaps also the shape of the wage-setting curve, leading to a hump-shaped relationship between unemployment and the degree of centralization of wage bargains in the general equilibrium. ${ }^{23}$

A detailed discussion of the impact of the degree of centralization on the wagesetting curve is clearly beyond the scope of this paper. However, we can analyse how the labor union's objective function has to be changed. Consider an economy where wage bargains take place between a central labor union and firms. In this case property (1) of our model is violated since the central labor union internalizes the externalities arising from the wage bargain. ${ }^{24}$ The wage bargain between the central labor union and firms determines the wage level for the whole economy. This implies that in Fig. $1 W_{1}$ has to be replaced by $W$. Moreover, there is no difference between $V$ and $V_{1}$ as well as between $\bar{V}$ and $\bar{V}_{1}$. Instead of eq. (16) one obtains

$$
V-\tilde{V}=\frac{1}{r+\delta}\left\{\omega(u) U(W)+[\tau(u)-\omega(u)] U(b W)-\tau(u) U\left(B_{t_{0}}\right)\right\}
$$

The central union internalizes the impact of higher wage demands on the unemployment rate, implying that $u$ is no longer considered to be exogenous in the wage bargain.

In the case of wage bargains at the industry level additionally property (2) is violated since bargaining units can be expected to behave strategically. In some countries, as for instance in Germany, one industry often has a leadership position affecting the bargaining outcome in other industries. If this is taken into account in the wage bargain of the leading industry, the external effects of wage bargaining are internalized similar to the case of a central labor union.

The results in this paper have been derived for a closed economy. In an open economy the wage bargaining process also affects the real exchange rate which is often associated with the competitiveness of an economy, see for instance Layard et al. (1991, ch. 8.4). This is taken into account in Beissinger and Büsse (2001) who analyse the wage bargaining outcomes within a two-country-model for different

\footnotetext{
${ }^{23}$ As argued by Danthine and Hunt (1994) and Flanagan (1999), the hump-shaped relationship may become rather flat in an open economy, implying that differences in bargaining structure are of less importance in open economies.

${ }^{24}$ See Calmfors (1993) for an enumeration of various external effects caused by the wage bargain.
} 
unemployment benefit systems and Cobb-Douglas technology. They show that changes in the benefit level in one country also affect the wage bargaining outcome in the other country. However, the wage-setting curve of each country exhibits the same shape as in the closed economy. Hence, it can be expected that our analysis is not invalidated in an open economy.

\section{Summary and conclusions}

We show how the analysis in a dynamic wage bargaining model has to be modified if in contrast to the literature it is assumed that firstly unemployment benefits are tied to the previous level of individually earned wages and secondly unemployment benefits of those already unemployed at the beginning of the bargaining period differ from benefits of those who become unemployed in later periods. For this aim we develop a dynamic wage bargaining framework which encompasses 'conventional' models of the literature as special cases. Focusing on a model with Cobb-Douglas production technology and risk-neutral workers, we demonstrate that in our model the result of a vertical wage-setting curve is not obtained. It is shown that a crucial prerequisite for a vertical wage-setting curve in an earnings-related benefit system is the assumption that unemployment compensation does not depend on the time period in which a worker becomes unemployed. If this assumption is abandoned, the wage-setting curve exhibits one of the following shapes depending on the parameter values: either the curve has a negative slope over the whole range of (permissible) unemployment rates or the curve exhibits a negative slope for low unemployment rates and has a positive slope for high ones. As a further result it follows from our analysis that wage claims are ceteris paribus. higher if unemployment benefits are a function of individual wages instead of the average wage level. The reason is that labor unions take into account that higher wages today imply higher benefits for its members tomorrow which leads to higher wage pressure.

We also examine how the wage-setting curve is affected by a variation in the parameters. For instance, we consider the consequences of labor market reforms which reduce unemployment benefits of those who become unemployed after the bargaining period, but keep the benefits of the currently unemployed unchanged. We show that such a policy leads to higher wage pressure and thus increases the equilibrium rate of unemployment. This result holds for both earnings-related and flat-rate benefit systems.

\section{Acknowledgements}

We would like to thank two anonymous referees, Lutz Arnold, Oliver Büsse, and Laszlo Goerke for useful comments and suggestions. We are especially grateful to Josef Falkinger for his very detailed and helpful comments on earlier versions of the paper. 


\section{References}

Alexander, C.O. and Ledermann, W. (1996). 'Are Nash bargaining wage agreements unique? An investigation into bargaining sets for firm-union negotiations', Oxford Economic Papers, $48,242-53$.

Altenburg, L. and Straub, M. (1998). 'Efficiency wages, trade unions, and employment', Oxford Economic Papers, 50, 726-46.

Beissinger, T. and Büsse, O. (2001). 'Bismarck versus Beveridge: which unemployment compensation system is more prone to labor market shocks?', FinanzArchiv, 58, 78-102.

Blanchard, O. and Kiyotaki, N. (1987). 'Monopolistic competition and the effects of aggregate demand', American Economic Review, 77, 647-66.

Calmfors, L. (1993). 'Centralisation of wage bargaining and macroeconomic performance: a survey', Economics Department Working Paper No. 131, OECD, Paris.

Calmfors, L., Booth, A., Burda, M., Checchi, D., Naylor, R. and Visser, J. (2001). 'The future of collective bargaining in Europe', in T. Boeri, A. Brugiavini, and L. Calmfors (eds), The Role of Unions in the Twenty-First Century, Oxford University Press, Oxford, 1-155.

Calmfors, L. and Driffill, J. (1988). 'Bargaining structure, corporatism and macroeconomic performance', Economic Policy, 6, 14-61.

Danthine, J.-P. and Hunt, J. (1994). 'Wage bargaining structure, employment and economic integration', Economic Journal, 104, 528-41.

Egger, H. (2002). 'Unemployment may be lower if unions bargain over wages and employment', Labour, 16, 103-33.

Flanagan, R.J. (1999). 'Macroeconomic performance and collective bargaining: an international perspective', Journal of Economic Literature, 37, 1150-75.

Hoel, M. (1991). 'Union wage policy: the importance of labour mobility and the degree of centralization', Economica, 58, 139-53.

Layard, R. and Nickell, S. (1990). 'Is unemployment lower if unions bargain over employment?', Quarterly Journal of Economics, 105, 773-87.

Layard, R., Nickell, S. and Jackman, R. (1991). Unemployment, Oxford University Press, Oxford.

Lever, M. and van Veen, T. (1991). 'Union wage setting, employment and investment: a survey of theory and empirical evidence', Labour, 5, 25-61.

Manning, A. (1991). 'The determinants of wage pressure: some implications of a dynamic model', Economica, 58, 325-40.

Manning, A. (1993). 'Wage bargaining and the Phillips curve: the identification and specification of aggregate wage equations', Economic Journal, 103, 98-118.

OECD (1999). Benefit Systems and Work Incentives, OECD, Paris.

Oswald, A.J. (1993). 'Efficient contracts are on the labour demand curve: theory and facts', Labour Economics, 1, 85-113.

Pencavel, J.H. (1985). 'Wages and employment under trade unionism: microeconomic models and macroeconomic applications', Scandinavian Journal of Economics, 87, 197-225.

Schömann, K., Flechtner, S., Mytzek, R. and Schömann, I. (2000). 'Moving towards employment insurance-unemployment insurance and employment protection in the 
OECD', Discussion Paper FS I 00-201, Wissenschaftszentrum Berlin für Sozialforschung, Germany.

Schmid, G. and Reissert, B. (1996). 'Unemployment compensation and labour market transitions', in J. O'Reilly and K. Schömann (eds), International Handbook of Labour Market Policy and Evaluation, Cheltenham and Northampton, 235-76.

\section{Appendix 1}

Derivation of the aggregate wage-setting curve

With $W_{1}=W$ it follows from eq. (23) that

$$
W=\frac{\mu \tau(u)}{\mu[\tau(u)+(1-b)(\psi(u)-\lambda(u))]-(1+\lambda(u) b)} B_{t_{0}}
$$

The denominator of this equation can be written as

$$
(1+\lambda(u) b)\left\{\frac{\mu \omega(u)\left[1-\lambda(u) b \frac{\psi(u)-\lambda(u)}{\lambda(u) \omega(u)}\right]}{1+\lambda(u) b}-1\right\}
$$

Due to the definitions in eq. (18) it holds that

$$
\frac{\psi(u)-\lambda(u)}{\lambda(u) \omega(u)}=-1
$$

If this is taken into account in eq. (A.2), the aggregate wage-setting curve can be written as in eq. (24).

\section{Appendix 2}

The slope of the aggregate wage-setting curve

Since $q(u) \equiv[1+\lambda(u) b][\mu \omega(u)-1]$, eq. (25) can be rewritten as

$$
\begin{aligned}
\frac{d W}{d u}= & q(u)^{-2} \mu\left\{\tau^{\prime}(u)[1+b \lambda(u)][\mu \omega(u)-1]\right. \\
& \left.-\tau(u)\left[\lambda^{\prime}(u) b(\mu \omega(u)-1)+(1+\lambda(u) b) \mu \omega^{\prime}(u)\right]\right\} B_{t_{0}}
\end{aligned}
$$

Hence

$$
\frac{d W}{d u}=q(u)^{-1} \mu\left\{\tau^{\prime}(u)-\tau(u)\left[\frac{\lambda^{\prime}(u) b}{1+b \lambda(u)}+\frac{\mu \omega^{\prime}(u)}{\mu \omega(u)-1}\right]\right\} B_{t_{0}}
$$


The derivatives $\tau^{\prime}, \lambda^{\prime}$ and $\omega^{\prime}$ are

$$
\begin{gathered}
\tau^{\prime}(u)=\frac{(r+\delta) \delta}{[(1-u) \delta+r u]^{2}}>0 \quad \lambda^{\prime}(u)=\frac{\delta^{2}}{[(1-u) \delta+r u]^{2}}>0 \\
\omega^{\prime}(u)=\frac{\delta(r+\delta)}{(r u+\delta)^{2}}>0
\end{gathered}
$$

Eq. (A.5) can be simplified by noting that

$$
\tau(u) \lambda^{\prime}(u)=\tau^{\prime}(u) \lambda(u)=\frac{\delta^{2} u(r+\delta)}{[(1-u) \delta+r u]^{3}}
$$

which leads to

$$
\frac{d W}{d u}=q(u)^{-2} \mu\left[\tau^{\prime}(u)(\mu \omega(u)-1)-\mu \tau(u) \omega^{\prime}(u)(1+b \lambda(u))\right] B_{t_{0}}
$$

The sign of $d W / d u$ depends on the sign of the expression in brackets. Taking the definition of the parameters in eq. (18) and the derivatives in eq. (A.6) into account it follows that

$$
\tau^{\prime}(u)(\mu \omega(u)-1)-\mu \tau(u) \omega^{\prime}(u)(1+b \lambda(u))=\frac{\mu(1-b)(r+\delta)^{2} u^{2} \delta^{2}-\delta(r+\delta)(r u+\delta)^{2}}{[(1-u) \delta+r u]^{2}(r u+\delta)^{2}}
$$

The sign of $d W / d u$ depends on the sign of the numerator of this expression, which leads to condition (26). 